\title{
Efectos retroactivos del acto invalidatorio: interpretación administrativa y judicial (Corte Suprema)
}

\author{
Comentario de Juan Pablo Leppe Guzmán
}

Santiago, catorce de mayo de dos mil trece.

VISTOS:

En estos autos Rol No 21.794-2010, juicio sumario sobre impugnación de acto administrativo invalidatorio, caratulados "Vásquez y otros con I. Municipalidad de Osorno", la parte demandante dedujo recurso de casación en el fondo en contra de la sentencia dictada por la Corte de Apelaciones de Valdivia que confirmó la de primer grado que rechazó la demanda.

Se trajeron los autos en relación.

\section{CONSIDERANDO:}

Primero: Que por medio del recurso de nulidad sustancial se denuncia la infracción de los artículos 52 y 53 de la Ley $\mathrm{N}^{\circ} 19.880$ sobre Procedimientos Administrativos basado en que si bien es efectivo que la Administración cuenta con facultades para invalidar un acto por ella emitido, el ejercicio de dicha facultad debe ser realizado conforme a lo que establece el segundo de los artículos individualizados. Agrega el recurrente que la sentencia impugnada reconoce, en su fundamento segundo, que el Alcalde de la Municipalidad de Osorno omitió la realización de un procedimiento invalidatorio, justificando dicha omisión en la circunstancia de que el Alcalde en cuestión daba estricto cumplimiento al Dictamen de Contraloría $\mathrm{N}^{\circ} 50142$ de 9 de septiembre de 2009.

Expresa el recurrente que su parte jamás ha desconocido que los dictámenes de la Contraloría General de la República son vinculantes para los municipios; empero, dicha circunstancia no exime a la autoridad de la obligación de cumplir con los requisitos legales para proceder a la invalidación de un acto administrativo, pues la denominada potestad invalidatoria supone necesariamente la existencia de un procedimiento administrativo, instancia en la cual los interesados puedan hacer valer sus derechos, razón por la que el legislador contempló la existencia de una audiencia previa de los mismos.

Refiere el recurso que al omitirse la realización del sumario administrativo, argumentándose para ello la circunstancia de estar cumpliendo un dictamen del órgano de 
control, se ha vulnerado la Ley $\mathrm{N}^{\circ} 19.880$, ya que se han invalidado sendos decretos alcaldicios sin una tramitación administrativa expresamente regulada en la ley, requisito que no reconoce excepción alguna.

En lo relativo a la vulneración del artículo 52 de la Ley $\mathrm{N}^{\circ} 19.880$ expone el recurrente que su infracción se produce por haberse dado efecto retroactivo al acto invalidatorio, cuestión prohibida por la norma, pues los efectos del mismo son evidentemente perjudiciales para los interesados desde que se traducen en la obligación de restituir las sumas que en su oportunidad fueron pagadas.

En virtud de lo reseñado afirma que el error denunciado influye sustancialmente en lo dispositivo del fallo, debiendo en consecuencia anularse la sentencia impugnada, dictarse sentencia de remplazo y en definitiva acoger la demanda interpuesta.

SEGUNDO: Que son hechos de la causa, por así haberlos establecido los jueces del grado en el motivo octavo de la sentencia de primera instancia, reproducido en alzada, y en el segundo de la de segunda instancia, los siguientes:

1. La dictación por parte de la demanda de los Decretos $\mathrm{N}^{\circ} 5204$ y N 5336 de 22 y 27 de julio de 2009, respectivamente, mediante los cuales dispuso el pago por concepto de reliquidación de incremento contemplado en el artículo 2 del D.L. $\mathrm{N}^{\circ} 3.501$ de 1980.

2. La dictación por la demandada del Decreto Exento $\mathrm{N}^{\circ} 7267$ de 5 de octubre de 2009, mediante el cual deja sin efecto los Decretos $\mathrm{N}^{\circ} 5204$ y N $\mathrm{N}^{\circ} 5336$, disponiendo el reintegro de los dineros indebidamente percibidos.

3. La dictación por parte de la Contraloría General de la República de la Resolución Exenta N 3702 de 12 de octubre de 2010 que dispone el reintegro de las sumas pagadas indebidamente por la Municipalidad de Osorno a cada uno de sus funcionarios, debiendo éstos restituir las sumas percibidas.

4. La omisión, por parte de la Municipalidad demandada, de la realización de un procedimiento invalidatorio.

Tercero: Que conforme a tales supuestos de hecho los jueces de la instancia estimaron, según aparece en los fundamentos decimotercero y decimocuarto de la sentencia de primer grado, que la exigencia de un procedimiento administrativo de carácter invalidatorio resulta errónea puesto que en el caso de autos "sólo hubo un acatamiento de los dictámenes de la Contraloría General de la República que observó un proceder incorrecto por parte del Municipio”, razón por la cual el actuar de la demandada "no se enmarcó dentro de un procedimiento administrativo de invalidación, ni podía hacerlo puesto que su materialización obedeció más bien a la culminación de otro procedimiento pretérito, motivado en virtud de los Decretos Alcaldicios No 5204 y $5336 ”$.

Tal razonamiento es corroborado por los sentenciadores de segunda instancia en el fundamento segundo de la sentencia impugnada, al señalar que la omisión en la realización del procedimiento se debe a que "dio - la demandada- estricto cumplimiento al dictamen 
de Contraloría N 50.142 de 9 de septiembre de 2009, en virtud de la obligación que tiene de cumplir los dictámenes emanados de la Contraloría General de la República, acorde lo disponen los artículos 1, 5, 6 y 9 de la Ley Orgánica de la Contraloría General de la República, en particular el inciso final del artículo 9, que establece que los informes de la Contraloría serán obligatorios para los funcionarios correspondientes en los casos concretos a que se refieran”.

CuARto: Que el acto administrativo terminal, en tanto manifestación de la actividad jurídica unilateral del Estado, es el producto de una concatenación o secuencia de actos trámites destinados a la dictación o constitución de un acto terminal que cuando ha sido dictado conforme a derecho produce todos sus efectos; por el contrario, cuando ha sido dictado con infracción al ordenamiento jurídico se origina su ineficacia, susceptible de remediarse ya sea por vía judicial o administrativa, opción esta última denominada genéricamente invalidación.

De lo anterior se desprende que la invalidación se erige como una forma de extinción del acto administrativo regida particularmente por lo dispuesto en el artículo 53 de la Ley $\mathrm{N}^{\circ} 19.880$.

Quinto: Que el inciso primero del artículo 53 de la Ley $\mathrm{N}^{\circ} 19.880$ dispone que: "La autoridad administrativa podrá, de oficio o a petición de parte, invalidar los actos contrarios a derecho, previa audiencia del interesado, siempre que lo haga dentro de los dos años contados desde la notificación o publicación del acto”. Así ha establecido como trámite necesario para invalidar un acto administrativo el requisito de la audiencia previa, con lo cual materializa el principio constitucional del justo y racional procedimiento contemplado en el numeral $3^{\circ}$ del artículo 19 de la Carta Fundamental, de forma que confiere a los interesados o afectados una oportunidad para que expongan sus argumentos en el procedimiento invalidatorio.

Sexto: Que frente a la ausencia de un procedimiento administrativo de invalidación desarrollado conforme a lo dispuesto en el artículo 53 de la Ley No 19.880 la demandada sostuvo la improcedencia del mismo, pues en su concepto en la especie sólo se está frente a un acto de corrección en virtud de lo resuelto en su oportunidad por la Contraloría General de la República, en contraposición a la alegación planteada por los demandantes que refirieron la necesidad de desarrollar dicho procedimiento.

SÉPTIMO: Que la controversia expuesta en el fundamento precedente carece de influencia en lo resolutivo, pues se encuentra acreditado en autos -antecedentes documentales de fojas 332 a 336- que en su oportunidad se escuchó a la Asociación de Profesionales y Técnicos Municipales de Osorno (ASPROTECMO) como también a la Asociación de Funcionarios Municipales de Osorno (ASFUMO), cumpliéndose con ello el requisito legal contemplado en el inciso primero del artículo 53 de la Ley $\mathrm{N}^{\circ} 19.880$, lo que se traduce en que resulta innecesario distinguir, en el caso en concreto, si se trata de acto invalidatorio o bien de mero cumplimiento de lo dispuesto por la Contraloría General 
de la República, ya que con los antecedentes referidos queda de manifiesto que en cualquier evento la exigencia contemplada en el citado artículo 53 que se denuncia como vulnerada se cumplió.

Octavo: Que tampoco concurre la infracción denunciada respecto del artículo 52 de la Ley $\mathrm{N}^{\circ} 19.880$, pues el supuesto necesario para se genere la limitación a los efectos retroactivos de un acto administrativo es que la afectación que se vaya a producir sea consecuencia de un acto válidamente emitido, cual no es el caso de autos.

Noveno: Que de lo que se viene razonando es posible concluir que la sentencia objeto del recurso no ha sido dictada con infracción de ley que haya influido sustancialmente en lo dispositivo del fallo, por lo que procede el rechazo del recurso deducido.

Por estas consideraciones y visto además lo dispuesto en el artículo 767 del Código de Procedimiento Civil, se rechaza el recurso de casación en el fondo interpuesto en el primer otrosí de fojas 375 en contra de la sentencia de dieciocho de noviembre de dos mil once, escrita a fojas 373 .

Regístrese y devuélvase.

Redacción a cargo del Ministro Sr. Carreño.

Rol No 12.195-2011.

Pronunciado por la Tercera Sala de esta Corte Suprema integrada por los Ministros Sr. Héctor Carreño S., Sr. Pedro Pierry A., Sra. María Eugenia Sandoval G., y los Abogados Integrantes Sr. Emilio Pfeffer U., y Sr. Jorge Lagos G. No firma, no obstante haber concurrido a la vista y al acuerdo de la causa, el Abogado Integrante señor Pfeffer por estar ausente. Santiago, 14 de mayo de 2013.

Autoriza la Ministra de Fe de la Excma. Corte Suprema.

En Santiago, a catorce de mayo de dos mil trece, notifiqué en Secretaría por el Estado Diario la resolución precedente.

\section{COMENTARio}

De la lectura del fallo transcrito se desprende que la Sala Constitucional de la Corte Suprema rechazó el recurso de casación en el fondo al estimar que los jueces del primer y segundo grado habían resuelto conforme a Derecho, básicamente, porque constaba en el expediente administrativo que se había oído a la parte recurrente antes de disponerse la invalidación, y porque aquella no podía verse perjudicaba en sus derechos si los actos invalidados no tenían la aptitud para crear o declarar tales derechos.

A mayor abundamiento, la Corte interpretó el artículo 52 de la Ley que Establece Bases de los Procedimientos Administrativos que Rigen los Actos de los Órganos de la 
Administración del Estado ${ }^{1}$, del modo que sigue: "Que tampoco concurre la infracción denunciada respecto del artículo 52 de la Ley $\mathrm{N}^{\circ} 19.880$, pues el supuesto necesario para que se genere la limitación a los efectos retroactivos de un acto administrativo es que la afectación que se vaya a producir sea consecuencia de un acto válidamente emitido, cual no es el caso de autos (considerando octavo)".

Criterio relevante no solo si atendemos al órgano que lo aplica y a la relectura que implica de una de las condiciones que exige la ley para dictar actos administrativos con efectos retroactivos (ley como la $\mathrm{N}^{\circ} 19.880$, de carácter supletorio); sino también si consideramos la incidencia que puede tener en la lectura que se haga en adelante del inciso final del artículo 13 de la Ley N 19.880 (“intereses de terceros") ${ }^{2}$, y su distancia con el criterio que aplica la Contraloría General de la República frente a supuestos similares.

El Órgano de Control incorpora en la operación hermenéutica el elemento de la buena fe y el principio de la confianza de los particulares, señalando que el ejercicio de la potestad invalidatoria "tiene como límite aquellas situaciones jurídicas consolidadas sobre la base de la confianza de los particulares en la actuación legítima de la Administración, de manera tal que las consecuencias de una medida de dicha naturaleza no pueden afectar a terceros que adquirieron derechos de buena fe al amparo del acto impugnado (dictamen $\mathrm{N}^{\circ} 31.798 / 2013$, aplicando criterio contenido en dictámenes $\mathrm{N}^{\mathrm{o}} 28.097 / 2011,64.271 / 2011,5.531 / 2010,32.357 / 2006$ y $56.479 / 2003$, entre otros)”.

Así, constatamos que el ejercicio de la potestad invalidatoria por la Administración y el alcance temporal del acto invalidatorio son materias que ha abordado la jurisprudencia administrativa y la jurisprudencia judicial. La primera, interpretando la excepción al principio de la irretroactividad de los actos en función de la situación subjetiva de los administrados; y la segunda (como vemos en el fallo reproducido), tomando como punto de partida de su razonamiento el análisis del acto que constituye o declara los derechos invocados por quien se opone a la invalidación.

1 "Retroactividad. Los actos administrativos no tendrán efecto retroactivo, salvo cuando produzcan consecuencias favorables para los interesados y no lesionen derechos de terceros".

2 "La Administración podrá subsanar los vicios de que adolezcan los actos que emita, siempre que con ello no se afectaren intereses de terceros”. 
